(c) 2020 Universidad Nacional Autónoma de México, Facultad de Estudios Superiores Zaragoza.

Este es un artículo Open Access bajo la licencia CC BY-NC-ND (http://creativecommons.org/licenses/by-nc-nd/4.0/).

TIP Revista Especializada en Ciencias Químico-Biológicas, 23: 1-13, 2020.

https://doi.org/10.22201/fesz.23958723e.2020.0.254

\title{
La milpa como modelo para el estudio de la microbiodiversidad e interacciones planta-bacteria
}

\author{
Gabriela Gastélum ${ }^{1,2}$ y Jorge Rocha ${ }^{3, *}$ \\ ${ }^{1}$ Centro de Investigación y Desarrollo en Agrobiotecnología Alimentaria, San Agustín \\ Tlaxiaca, Hidalgo, México. ${ }^{2}$ Departamento de Ciencia de los Alimentos, Centro de \\ Investigación en Alimentación y Desarrollo A.C., Hermosillo, Sonora, México. \\ ${ }^{3}$ CONACYT- Centro de Investigación y Desarrollo en Agrobiotecnología Alimentaria, \\ San Agustín Tlaxiaca, Hidalgo, México. E-mail: *jorge.rocha@ciad.mx
}

\begin{abstract}
RESUMEN
La microbiología agrícola busca reemplazar a los agroquímicos por microorganismos o sus productos como agentes de control biológico, debido a que el uso de tecnologías de la revolución verde tiene efectos negativos sobre el ambiente, los productores y sus familias, los consumidores y la salud de los cultivos. Sin embargo, el conocimiento actual acerca de las interacciones benéficas planta-bacteria en ambientes complejos es limitado e insuficiente, para lograr el éxito esperado de los productos biológicos. Las milpas son agroecosistemas tradicionales donde se cultivan diversas variedades de maíz nativo con otras especies asociadas; no se utiliza riego, ni labranza y aunque su aplicación va en aumento, comúnmente no se utilizan agroquímicos; por esto, la milpa representa una fuente de conocimiento sobre prácticas sustentables. Recientemente, se han descrito cambios en las comunidades microbianas de los sistemas agrícolas a causa de la modernización y a la domesticación de las plantas. En la milpa, también se han identificado interacciones benéficas planta-bacteria que parecen haberse perdido en los cultivos modernos. En esta revisión, discutimos las estrategias clásicas y modernas de la microbiología agrícola que pueden ser aplicadas en el estudio de la milpa. El establecimiento de la milpa como modelo de estudio de las interacciones planta-bacteria puede resultar en la generación del conocimiento necesario para disminuir el uso de agroquímicos en los sistemas agrícolas modernos, así como evitar su creciente uso en las milpas. Palabras clave: agroecosistema milpa, microbiología agrícola, comunidades bacterianas.
\end{abstract}

\section{Milpas as a model for studying microbiodiversity and plant-microbe interactions}

\begin{abstract}
Research on agricultural microbiology aims at replacing agrochemicals with microorganisms or their natural products as biological control agents, since the use of technologies from the green revolution have had negative effects on the environment, on farmers and their families, the consumer, and on crop health. However, our current understanding about the beneficial microbe-plant interactions that mediate plant health in complex, natural settings is insufficient to achieve the success of these biological products. Milpas are traditional agroecosystems where several maize landraces are produced, together with other associated species. Technologies from the green revolution such as agrochemicals are largely absent in milpas, and therefore they represent a source of traditional knowledge on sustainable practices for agriculture. Recent studies show that modernization, as well as plant domestication cause disturbances in microbial communities from agroecosystems. Furthermore, unique beneficial bacteria-plant interactions occur in milpas, which may have been lost in modern agroecosystems. In this review, we discuss classic and modern research strategies from agricultural microbiology that can be applied in the study of milpas. Adopting milpas as a model habitat for microbe-plant interactions could result in the generation of knowledge that leads to decrease the use of agrochemicals in modern agroecosystems, as well as avoiding their growing use in milpas.
\end{abstract}

Keywords: milpa agroecosystem, agricultural microbiology, bacterial communities. 


\section{INTRODUCCIÓN}

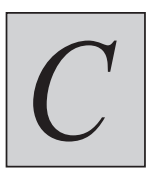

omo parte de la domesticación de los cultivos que son la base de nuestra alimentación (maíz en Mesoamérica, trigo en el Medio Oriente y arroz en Asia), se desarrollaron prácticas agrícolas que se perfeccionaron a lo largo del tiempo. Este es el caso de la milpa, un agroecosistema que se ha preservado generación tras generación por milenios en todo México y Sudamérica (Lozada-Aranda et al., 2018). En la milpa, se siembran diferentes variedades nativas de maíz como cultivo principal, y otras especies asociadas como la calabaza, frijol, jitomate y chile; además se permite el crecimiento de hierbas comestibles como los quelites (Lozada-Aranda et al., 2018; Rodríguez \& Arias, 2014) (Figura 1).

La milpa se ha adaptado a diferentes condiciones ambientales debido a que los agricultores han seleccionado semillas durante generaciones y experimentado con ellas en cada ciclo. Esta selección no se basa solamente en términos de productividad, sino también en el crecimiento de la planta, su adaptación a diferentes ambientes, su uso en los alimentos preparados en cada región y su empleo en las celebraciones, entre otros atributos. Es decir, cada sociedad ha domesticado especies con diferentes características en sus milpas de acuerdo a sus necesidades, cultura y tradiciones (Lozada-Aranda et al., 2018). La importancia de la milpa no se limita a la producción de alimentos, porque además, se obtienen plantas medicinales, materiales para construcción, etc., y también es parte de la vida diaria de los campesinos, de su organización y tejido social. Las familias enteras (el núcleo y los parientes) participan en la siembra, cuidado y cosecha de la milpa, por lo que se le denomina agricultura familiar (Salcedo, De La O \& Guzmán, 2014; Santillán, 2014). Las comunidades organizan festividades a lo largo del ciclo agrícola, para que la tierra sea fértil, para que llueva y para agradecer la cosecha, entre otras. La milpa tiene como fundamento la diversidad, tanto de especies como de variedades de maíz (Figura 1) así como la convivencia y respeto del hombre a la naturaleza.

Con el crecimiento de la población mundial surgió la necesidad de crear nuevas tecnologías para dar paso a la agricultura moderna e intensiva. Estas tecnologías están destinadas a la fertilización de las plantas, control de plagas y enfermedades, irrigación, obtención de variedades mejoradas y manipulación genética, entre otras. De esta manera, se logró incrementar el rendimiento de alimentos para abastecer a la población humana (Matson, Parton, Power \& Swift, 1997) y facilitar su distribución en zonas urbanizadas. De aquí que
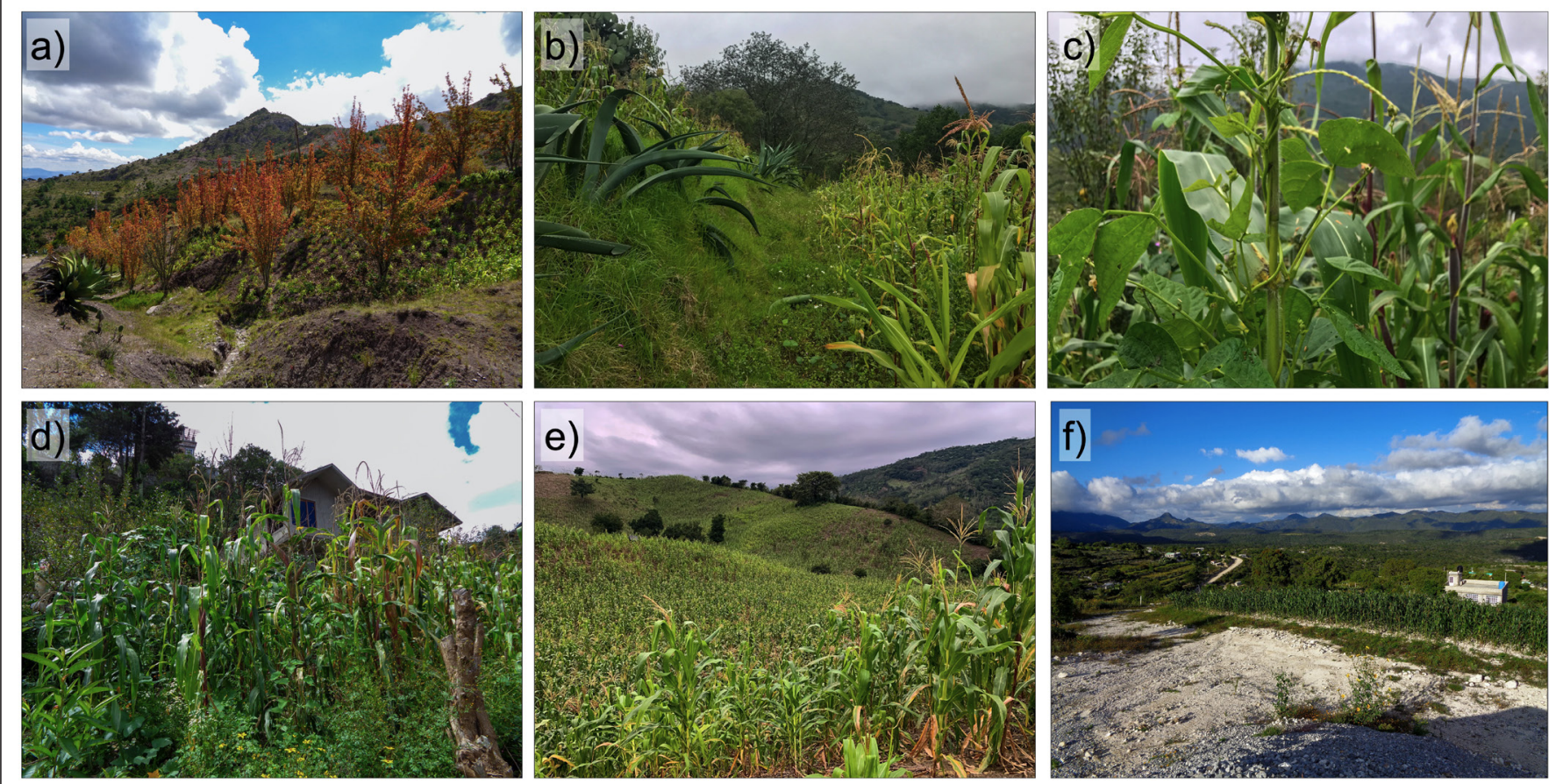

Figura 1. Milpas del estado de Hidalgo, México. a) Milpa en El Nogal, Ixmiquilpan; el maíz se encuentra asociado con árboles de pera; b) Milpa en el Boxo, Cardonal; la milpa está delimitada por plantas de maguey; c) Milpa en el Boxo, Cardonal; el maíz está asociado a plantas de frijol; d) Milpa en Cuesta Colorada, Ixmiquilpan; e) Milpa en Huitzizilingo, Orizatlán; f) Milpa en Eı Pinalito, Cardonal. Las comunidades bacterianas en el suelo de la milpa en el Boxo, mostrada en b) y c), han sido descritas por (Aguirre-Von-Wobeser et al., 2018). Fotografías: (a), (d) y (f), de Juan Pablo Pérez, CIDEA, Pachuca. 
el fundamento de la agricultura moderna sea el monocultivo (variedades genéticamente homogéneas) en alta densidad y la globalización (Tilman, Balzer, Hill \& Befort, 2011).

En la milpa, la siembra simultánea de distintas variedades de maíz nativo en asociación con otros cultivos, las prácticas de labranza mínima y la nula presencia de agroquímicos, han mantenido una muy alta diversidad de animales, plantas y microorganismos en el suelo del ecosistema (Figura 2) (Ebel, Pozas Cárdenas, Soria Miranda \& Cruz González, 2017; Rebollar et al., 2017). Esto último, contrasta con la biodiversidad microbiana disminuida en los monocultivos agrícolas modernos. Por lo tanto, en la milpa se favorecen interacciones ecológicas (CONABIO, 2020), que parecen estar estrechamente relacionadas con la salud, o equilibrio de los ecosistemas (Stukenbrock \& McDonald, 2008). En México, el área dedicada a cultivos de temporal manejados por campesinos alcanza un $74 \%$ del área total cultivada, que contribuye con el 56\% de la producción de maíz (Jerónimo, 2009); sin embargo, la productividad en la milpa se extiende a otras especies de plantas y hierbas. Por ende, la generación de conocimiento científico es prioritaria para la preservación de los agroecosistemas tradicionales, así como para aumentar el rendimiento de las cosechas de manera sustentable.
Los microorganismos juegan un papel vital en la sanidad de las plantas. En este sentido, es probable que cuando nuestros ancestros domesticaron el maíz y otras especies en la milpa, también domesticaron inadvertidamente a los microorganismos que contribuyen benéficamente al desarrollo de las plantas (Tkacz et al., 2020). La milpa ha sido propuesta para el estudio in situ de la influencia de la domesticación sobre la evolución de las plantas, específicamente del maíz (Chen, Shapiro, Benrey \& Cibrián-Jaramillo, 2017). Asimismo, el microbioma de la milpa podría ser tanto un acervo genético sustancialmente distinto al de los agroecosistemas modernos como un ecosistema modelo para el estudio de la diversidad e interacciones de los microorganismos del suelo y los que se asocian a las plantas.

Para ofrecer un panorama sobre el establecimiento de la milpa como modelo de estudio de las comunidades microbianas y sus interacciones con las plantas, en este artículo revisamos los cambios en el microbioma de los agroecosistemas ocasionados por la modernización y la domesticación. También proponemos esfuerzos que la microbiología agrícola debe dirigir hacia el estudio de las interacciones plantabacteria en la milpa y el desarrollo de nuevas tecnologías para lograr una agricultura sustentable.

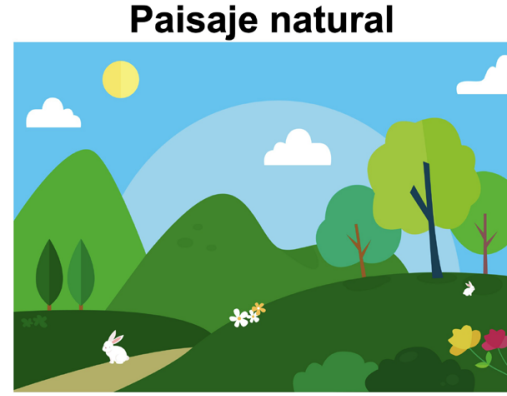

Paisaje heterogéneo, con alta diversidad de plantas, insectos y presencia de barreras naturales contra patógenos.

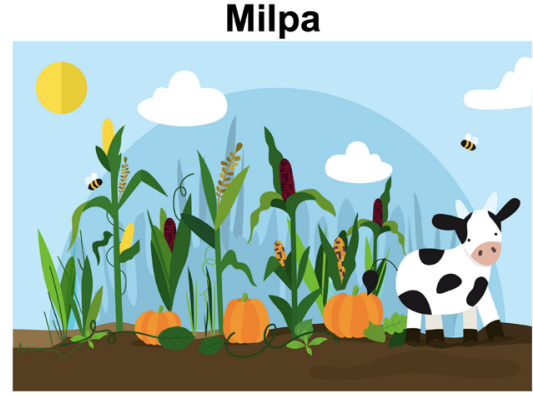

Agroecosistema de temporal y labranza nula o mínima, con maíz y otras especies asociadas, sin uso de agroquímicos y con fauna tolerada.

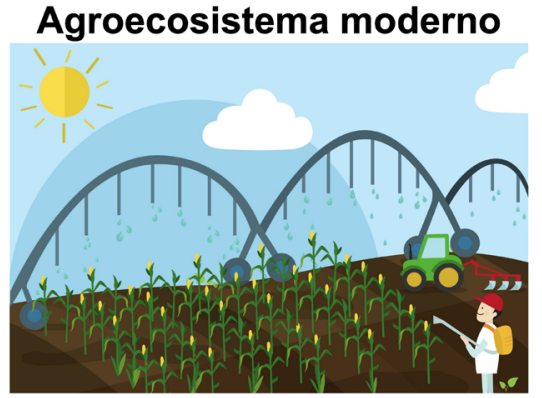

Paisaje homogéneo, con baja diversidad (monocultivo) y alta densidad de plantas, labranza intensiva, y uso de agroquímicos en alta cantidad.

\section{Milpas \\ Baja susceptibilidad a enfermedades y plagas}

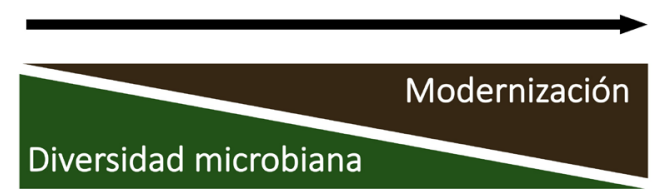

\section{Monocultivos}

\section{Pérdidas económicas por} enfermedades y plagas

Figura 2. Representación de un paisaje natural, una milpa y un agroecosistema moderno, donde se resaltan sus características ecológicas. Arriba: contraste entre un paisaje natural o no intervenido (izquierda), una milpa (centro) y un agroecosistema moderno (derecha). La adopción de prácticas modernas en sistemas agrícolas modernos (ejemplificadas por el riego, uso de maquinaria, monocultivo y aplicación de fertilizantes) va acompañada de una visible reducción en la diversidad de plantas y animales. Abajo: el gradiente de modernización está inversamente relacionado a la microbiodiversidad en los agroecosistemas, lo que impacta en la susceptibilidad a enfermedades. La ilustración fue realizada por: Zahira Zorrilla. 


\section{LAS BACTERIAS DEL SUELO: DEL AISLAMIENTO A LAS COMUNIDADES}

El suelo es uno de los ecosistemas donde se ha estudiado con amplitud la diversidad microbiana; sin embargo, la estructura y función de la microbiota en las milpas aún no se conoce a profundidad. La gran diversidad microbiana en el suelo y su inmensa complejidad, hacen que su estudio sea tanto un reto científico como una inspiración para los investigadores. Wilson (1994), sugirió que el suelo es un nicho de oportunidades para realizar estudios de ecología microbiana, debido a la complejidad de las comunidades presentes. Por ejemplo, se estima que en una muestra de $1 \mathrm{~g}$ de suelo hay alrededor de 4,000 genomas bacterianos diferentes (Torsvik, Goksøyr \& Daae, 1990).

La mayoría de los pequeños productores que trabajan en las milpas, por ejemplo, los del estado de Hidalgo, México, reconocen el suelo como un hábitat complejo y no sólo como un soporte físico para las plantas. Ellos saben que la aparición de enfermedades y plagas es consecuencia de procesos biológicos. Están al tanto de los desarrollos tecnológicos que pueden aumentar el rendimiento de las cosechas; sin embargo, consideran que el uso de maquinaria, fertilizantes o pesticidas químicos puede dañar la calidad del suelo. Por esto, los productores opinan que el aumento de la productividad no justifica el riesgo de deteriorar el suelo y disminuir la biodiversidad en la milpa, características que les permite tener alimentos variados durante gran parte del año (Santillán, 2014).

En este sentido, la microbiota de la milpa no ha sufrido cambios extraordinarios a lo largo del tiempo. Es mediante el estudio de sus funciones (ya sea en cultivos puros o en comunidades), que se podrían descubrir nuevas cepas, generar conocimiento sobre novedosos procesos fisiológicos y ecológicos de las bacterias y sus comunidades, así como aplicaciones en diversos campos de la biotecnología. Además, la milpa es un entorno ideal para el estudio de la evolución de la microbiota en respuesta a la domesticación de las plantas, ya que ahí, el proceso ha sido distinto al de cualquier otro ecosistema.

\section{Microorganismos en cultivos puros}

En la naturaleza, los microorganismos se encuentran en comunidades mixtas de alta complejidad, sin embargo, el conocimiento detallado sobre cada especie microbiana se consigue mediante el estudio de las cepas aisladas y en cultivos axénicos o puros. Haciendo uso de este tipo de cultivos se pueden diseñar experimentos para asociar genes, proteínas o metabolitos, con las funciones del microorganismo que pudieran tener aplicaciones en la agricultura y en el área de la salud, entre otras (Agaisse \& Lereclus, 1995; Depoorter et al., 2016; Dowling \& O'Gara, 1994; Kremmydas, Tampakaki \& Georgakopoulos, 2013) (Figura 3, izquierda). Existe una gran diversidad de microorganismos en el suelo que establecen interacciones benéficas con las plantas, ya sea mediante la limitación de la interacción planta-patógeno o plaga (hongos e insectos), a través de la promoción del crecimiento vegetal o al aumentar su tolerancia al estrés biótico o abiótico (Berendsen, Pieterse \& Bakker, 2012; Bulgarelli, Schlaeppi, Spaepen, Van Themaat \& Schulze-Lefert, 2013). Por ejemplo, las bacterias fijadoras de Nitrógeno $\left(\mathrm{N}_{2}\right)$ establecen interacciones benéficas, ya que son capaces de tomar $\mathrm{N}_{2}$ atmosférico y transformarlo en amonio $\left(\mathrm{NH}_{4}\right)$ para que las plantas lo puedan utilizar (Bargaz, Lyamlouli, Chtouki, Zeroual, \& Dhiba, 2018; Hirsch \& Mauchline, 2015). Un gran número de bacterias son capaces de fijar $\mathrm{N}_{2}$. Algunas establecen relaciones simbióticas con las plantas y forman nódulos en las raíces de las leguminosas (bacterias del orden Rhizobiales) (Franche, Lindström \& Elmerich, 2009; Liu, Contador, Fan \& Lam, 2018; Mus et al., 2016). Otras, se encuentran de forma libre en la rizosfera de otras plantas (bacterias de los géneros Azospirillum o Azotobacter) o dentro de ellas como endófitos (bacterias del género Herbaspirillum) (Bhattacharyya \& Jha, 2012; Mus et al., 2016). Entre los microorganismos capaces de controlar plagas, destacan Bacillus thuringiensis - una bacteria entomopatógena - y Thrichoderma sp. - hongos con actividad antifúngica - (Benítez, Rincón, Limón \& Codon, 2004; Milner, 1994; Sanchis, 2011). Finalmente, especies como Bacillus subtilis o bacterias del género Pseudomonas son promotoras del crecimiento vegetal (Sivasakthi, Usharani, \& Saranraj, 2014).

Lo anterior, es conocimiento que se generó gracias a los estudios en cultivos puros de hongos y bacterias en el laboratorio y que dio lugar a la producción de inoculantes comerciales. Estos consisten en formulaciones con microorganismos, de los cuales, muchos son casos de éxito, ya que se han aplicado ampliamente en el campo (Clayton et al., 2004; Mauro, Garcia-Cela, Pietri, Cotty \& Battilani, 2018). Los inoculantes son alternativas naturales para evitar o disminuir el uso de agroquímicos y fertilizantes. Sin embargo, a pesar de lo descrito sobre los mecanismos moleculares que dirigen las funciones benéficas de los microorganismos en cultivos puros, y después de décadas de desarrollo biotecnológico y comercialización, su aplicación en el campo aún representa un gran reto. Por ejemplo, con frecuencia los microorganismos no son aplicados en la cantidad suficiente, son desplazados por otras especies del suelo o requieren condiciones específicas para llevar a cabo el efecto deseado (Mitter, Brader, Pfaffenbichler \& Sessitsch, 2019). Esta baja calidad en los productos da como resultado la pérdida de confianza de los productores (Herrmann \& Lesueur, 2013) por lo que, en su estado actual de desarrollo, la aplicación de inoculantes dista de ser la solución que alivie el excesivo uso de agroquímicos y cubra la necesidad de incrementar la productividad agrícola de manera sustentable (Qiu, Egidi, Liu, Kaur \& Singh, 2019). En resumen, el éxito de los inoculantes no depende únicamente del conocimiento detallado de la fisiología de las bacterias 


\section{Bacterias aisladas \\ Comunidad sintética}

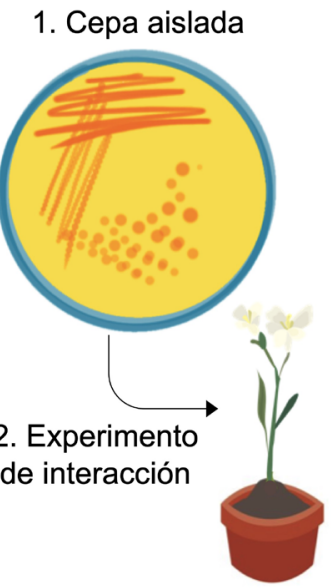

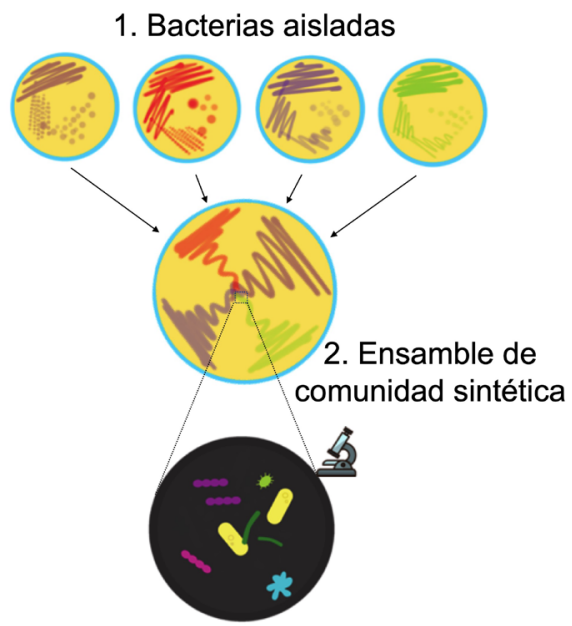

3. Evaluación de las funciones de la comunidad sintética
Metagenómica

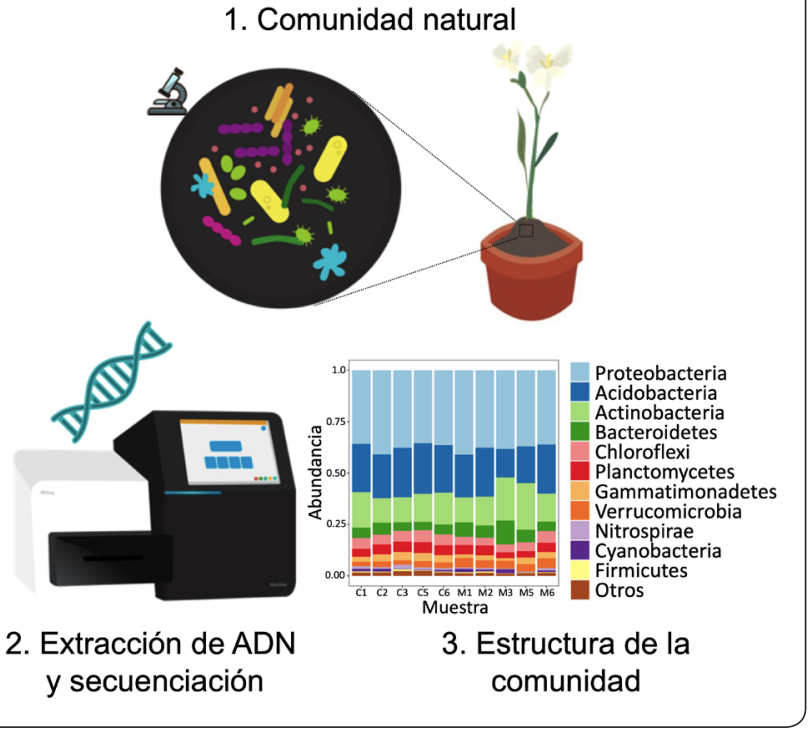

Figura 3. Estrategias dependientes e independientes de cultivo en laboratorio para el estudio de las funciones, interacciones y estructura de las comunidades bacterianas en la milpa. Izquierda: los estudios con bacterias se basan en cultivos puros/axénicos (1), que pueden ser utilizados directamente en ensayos de interacciones, por ejemplo, para observar en una planta sus funciones benéficas o de virulencia (2). Centro: a partir de aislados bacterianos (1), se pueden utilizar diversas estrategias para ensamblar una comunidad sintética (2); posteriormente, mediante ensayos utilizando a las comunidades bacterianas se pueden detectar nuevas propiedades (3). Derecha: en los estudios con comunidades bacterianas naturales por metagenómica, se obtiene DNA de una muestra natural (1), y a través de una secuenciación masiva, se obtiene la información genética (2) que después puede ser utilizada para estudiar la estructura de la comunidad (3). El gráfico de abundancias relativas correspondiente a la "estructura de la comunidad", fue tomado de (Aguirre-Von-Wobeser et al., 2018). La ilustración fue realizada por: Zahira Zorrilla.

benéficas obtenido a partir de cultivos puros en el laboratorio. Esta es una conclusión recurrente en la literatura donde se discute el descubrimiento de diversos microorganismos con actividad biológica y uso en la agricultura (Howell, 2003; Sinclair \& Nogueira, 2018; van Veen, van Overbeek \& van Elsas, 1997).

Algunos trabajos de investigación se han enfocado en abordar este tipo de cuestionamientos. Por ejemplo, se ha estudiado el destino de las células bacterianas una vez que se aplican en el suelo (van Veen et al., 1997) y el uso de bacterias nativas adaptadas a las condiciones ambientales, para afrontar problemas locales de plagas y enfermedades (Howell, 2003; Santhanam, Weinhold, Goldberg, Oh \& Baldwin, 2015). También se ha comenzado a explorar el efecto de las interacciones bacteria-bacteria sobre la actividad biológica de interés, esto es: cómo se comportan las bacterias una vez que están en contacto con la microbiota del suelo (Kaminsky, Trexler, Malik, Hockett \& Bell, 2019). Muchos de estos aspectos ecológicos quedan fuera del alcance de los estudios con bacterias en cultivos puros, por lo que es necesario incorporar estrategias experimentales que consideren a las bacterias de interés como parte de los complejos microbiomas del suelo, de la rizosfera o como endófitas de las plantas.
La milpa, con sus características ecológicas únicas, podría ser una fuente de cepas microbianas con actividad biológica y potencial biotecnológico (Aguirre-Von-Wobeser, RochaEstrada, Shapiro \& De La Torre, 2018; Rebollar et al., 2017; Van Deynze et al., 2018)(Figura 3). Para que el efecto de la aplicación de inoculantes sea efectivo, se debe considerar no sólo el estudio de las interacciones bipartitas (bacteriahospedero, bacteria-patógeno o bacteria-plaga) en ambientes controlados, sino también en ambientes complejos (Kaminsky et al., 2019; Mitter et al., 2019). Los microorganismos son capaces de producir moléculas - como resultado de su metabolismo - con una gran variedad de estructuras químicas y actividades biológicas, entre las que destacan las propiedades antibióticas (Woodruff, 1980). Por lo tanto, es indispensable estudiar también los efectos que tienen los productos naturales con actividad biológica en el contexto ambiental de interés, con el fin de no ocasionar un desbalance ecológico indeseable.

\section{Microorganismos en comunidad}

Con el estudio de las bacterias en comunidades, por ejemplo en sus hábitats naturales, se pretende entender la biología de estos microorganismos en entornos complejos, muchas veces mediante el análisis de muestras ambientales (Ghosh, Mehta \& Khan, 2019). Las muestras ambientales se toman directamente del entorno que se desea estudiar, por ejemplo, 
de cuerpos de agua, del aire, del suelo, de la vegetación o de los alimentos, y posteriormente, se analizan con estrategias de investigación independientes al cultivo en el laboratorio. La principal aportación de estas estrategias es el conocimiento de la estructura de las comunidades microbianas en el ambiente, esto es, la identificación de grupos taxonómicos y la cuantificación de su abundancia relativa a partir de la información genética que se obtiene directamente de ellas en una muestra ambiental. De esta manera, el estudio de estas comunidades es una ventana al entendimiento de su evolución (Fierer, 2017) (Figura 3, derecha).

En la actualidad, existen numerosos avances en las técnicas de amplificación y secuenciación masiva del DNA (Levy \& Myers, 2016; Méndez-García, Bargiela, Martínez-Martínez \& Ferrer, 2018). Esto permite la identificación de los individuos en comunidades bacterianas a nivel de género o especie, de acuerdo a la profundidad de la técnica que se utilice. Los estudios metagenómicos actuales consisten en la extracción del DNA directamente de una muestra ambiental y su secuenciación con plataformas de secuenciación masiva o Next Generation Sequencing.

La identificación molecular de los microorganismos se puede realizar de distintas maneras. Por ejemplo, durante décadas se han utilizado técnicas dependientes de marcadores moleculares - genes cuya baja tasa de mutación nos permite diferenciar entre grupos taxonómicos - como el gen que codifica para la subunidad ribosomal 16S (16S rRNA) (Woese, 1987). Aunque la secuenciación de $16 \mathrm{~S}$ rRNA en la actualidad es una estrategia muy utilizada para la identificación de aislados bacterianos y para el estudio de la biodiversidad en comunidades bacterianas, esta tiene una baja resolución taxonómica. Es decir, en ocasiones es difícil hacer distinciones entre algunas especies (Janda \& Abbott, 2007). Por lo anterior, a partir del nivel de profundidad deseado en la identificación, es posible utilizar otras técnicas con mayor resolución como Multilocus Secuence Typing (MLST) o secuenciación Shotgun (Maiden, 2006; Quince, Walker, Simpson, Loman \& Segata, 2017). MLST consiste en la identificación de la variabilidad de, por lo general, 5 a 10 genes housekeeping - genes constitutivos necesarios para mantener el funcionamiento celular básico -, para identificar microorganismos a nivel de especies o subespecies. Por último, la secuenciación Shotgun consiste en secuenciar todos los genes de los individuos en una muestra ambiental y ensamblar cada uno de sus genomas a través de herramientas bioinformáticas. De esta manera, se alcanza una identificación aún más profunda, a nivel de cepas, e incluso se pueden predecir muchas de sus funciones.

Las estrategias preferidas por los investigadores para el estudio del microbioma en suelos son la secuenciación del gen 16S rRNA y la secuenciación Shotgun (Fierer, 2017). Estos métodos nos permiten conocer la abundancia relativa de los taxas presentes en la muestra o de genes funcionales de interés, respectivamente. Se ha encontrado que la estructura del microbioma del suelo es variable de acuerdo al tipo de suelo y otros factores bióticos (presencia de plantas) y abióticos (pH, humedad, salinidad, etc.) (Thompson et al., 2017). Es por esto que, al estudiar el microbioma de suelos de diferentes sitios - y con características distintas - y correlacionarlos con estos factores, es posible detectar patrones que expliquen las variaciones específicas en las comunidades microbianas. También es posible sugerir funciones y las reglas ecológicas generales que definen la diversidad y el ensamblaje de esas comunidades microbianas (Thompson et al., 2017).

Algunos grupos bacterianos aparecen en la gran mayoría de las muestras de suelo, y son considerados miembros centrales de la microbiota (core microbiome); estas especies bacterianas tienen una función esencial en ese hábitat por lo que están presentes en muestras de cualquier tipo de suelo. Conocer los miembros centrales de un hábitat es importante porque son indicadores de microbiodiversidad adecuada y por consiguiente, se puede determinar si el ecosistema se encuentra en buen estado (Shade \& Handelsman, 2012). Los grupos taxonómicos encontrados con mayor frecuencia en el suelo, son los phyla Acidobacteria, Verrucomicrobia, Bacteroidetes, Proteobacteria, Planctomycetes, Actinobacteria y Firmicutes (Fierer, 2017; Lundberg et al., 2012; Pershina et al., 2018; Thomas, Hehemann, Rebuffet, Czjzek \& Michel, 2011). La microbiodiversidad del suelo es uno de los factores que definen el ensamble de comunidades microbianas de la rizosfera (Lundberg et al., 2012), las cuales establecen relaciones más estrechas con las plantas. Otros factores que influyen en esta selección de microorganismos y su abundancia son: la especie de la planta hospedera, su estado fenológico, o la presencia de enfermedades (Lundberg et al., 2012). Por otro lado, también existen comunidades bacterianas capaces de colonizar endofíticamente a las plantas. Estas son más estables y con menor diversidad (Bulgarelli et al., 2012), y su ensamble depende en menor media de la diversidad inicial de bacterias en el suelo.

Las comunidades bacterianas en la rizosfera se han estudiado en plantas de maíz, principalmente en variedades híbridas. En la rizosfera de algunas variedades híbridas aumenta la presencia de Proteobacterias - con respecto a su abundancia en el suelo - y se excluyen especies de los grupos Acidobacteria, Chloroflexi, Planctomycetes, y Verrucomicrobia (Peiffer et al., 2013). En otras, se ha reportado que los phyla más abundantes son Proteobacteria, Firmicutes, Bacteroidetes, y Actinobacteria, siendo Bacteroidetes el único grupo enriquecido con respecto al microbioma del suelo (Niu, Paulson, Zheng \& Kolter, 2017). Además, el phylum Proteobacteria es más abundante dentro de las raíces, lo que sugiere que las bacterias de este grupo establecen interacciones importantes con el maíz como endófitas. Por otro lado, existen 
escasos estudios donde se han identificado los microbiomas asociados a variedades nativas de maíz. En un estudio realizado en milpas en Tlaxcala, México (Rebollar et al., 2017) se encontró que los phyla dominantes en el suelo cercano a la rizosfera son Proteobacteria, Actinobacteria, Acidobacteria, Gemmatimonadetes, y Verrucomicrobia. Además, nuestro estudio en milpas de Hidalgo indica que bacterias de los phyla Verrucomicrobia, Actinobacteria y del orden Burkholderiales (del phylum Proteobacteria) son seleccionados por las raíces de las plantas de maíz (Aguirre-Von-Wobeser et al., 2018).

Los estudios anteriores muestran que existen diferencias entre el ensamble de comunidades asociadas a variedades de maíz híbridas y nativas. Por ejemplo, el papel aparentemente contrario del grupo Verrucomicrobia, que se excluye de la raíz de maíces híbridos (Peiffer et al., 2013), pero se enriquece en la raíz de maíces nativos (Aguirre-Von-Wobeser et al., 2018); por lo que se puede inferir que las interacciones planta-bacteria pueden diferir en ambos tipos de maíz. Recientemente, se estudió la microbiota de una variedad de maíz criollo de la sierra Mixe en Oaxaca (Van Deynze et al., 2018) y se identificaron especies de bacterias fijadoras de nitrógeno asociadas al mucílago de las raíces aéreas; esto demuestra que los microorganismos asociados a maíces nativos pueden establecer interacciones con la planta que no son comunes en los maíces híbridos. En este caso, la interacción contribuye a la fijación de nitrógeno de la atmósfera, ya que este es un elemento escaso en el suelo.

Estas diferencias, que sólo pueden ser detectadas mediante aproximaciones de una investigación a nivel de comunidades bacterianas (metagenómica, secuenciación masiva, metatranscriptómica e identificación taxonómica), son un indicio de cómo la modernización y la domesticación pueden modificar las interacciones bacteria-bacteria y planta-bacteria. Aún quedan muchas preguntas por explorar para lograr entender la estructura y las funciones de las comunidades bacterianas asociadas al maíz en milpas; sin embargo, estos trabajos sientan las bases para consolidar a la milpa como un modelo para el estudio de las interacciones planta-bacteria.

\section{LA ACTIVIDAD HUMANA Y LA MICROBIOLOGÍA AGRÍCOLA EN LA MILPA}

Los seres humanos modificamos profundamente nuestro entorno a través de la agricultura. Sin embargo, la implementación de prácticas nocivas para el ambiente comenzó durante la segunda mitad del siglo XX, con la revolución verde (Khush, 2001). Por ejemplo, la introducción de fertilizantes, pesticidas químicos y maquinaria; el modelo económico de la industrialización y la globalización; la creación de variedades mejoradas; el uso del monocultivo en alta densidad, etc. (Figura 1). Estas prácticas han ocasionado que la agricultura moderna no sea sustentable, por disminuir la fertilidad del suelo, la biodiversidad y contribuir a que la agricultura actual emita el 50\% de gases de efecto invernadero a nivel mundial (Hathaway, 2016).

Adicionalmente, existen varias desventajas biológicas en los agroecosistemas modernos; por ejemplo, los monocultivos son más susceptibles a la presencia de enfermedades emergentes y de plagas resistentes a los agroquímicos, en comparación con las plantas silvestres en ambientes naturales o a las especies en agroecosistemas tradicionales como la milpa (Figura 2). Los fenómenos que causan estas limitaciones son un campo de estudio en desarrollo; sin embargo, se han descrito algunos mecanismos que las explican parcialmente. En un monocultivo, cuando una población bacteriana invade de manera virulenta a una planta, se encuentra con una extensión de territorio donde todas las plantas son igualmente susceptibles, dado que son genéticamente homogéneas (Stukenbrock \& McDonald, 2008) y sembradas en una alta densidad, físicamente cercanas unas a otras. De igual manera, se ha descrito que, al seleccionar semillas para una mayor productividad en los monocultivos, se modifica la genética de las plantas (Pérez-Jaramillo, Mendes \& Raaijmakers, 2016) y posiblemente su fisiología, lo que modifica la estructura e interacciones de la microbiota.

La aplicación de fertilizantes y plaguicidas también incrementan la susceptibilidad de las plantas a las enfermedades. Estos reducen la biodiversidad en el sistema (eliminan insectos benéficos, hierbas, etc.), por lo tanto, se promueve la virulencia del patógeno emergente (plaga, hongos o virus) a falta de enemigos naturales que limiten su dispersión o transmisión (Matson et al., 1997). Por último, la presencia de especies de plantas cultivadas fuera de sus centros de origen - derivado de la globalización - también tiene consecuencias importantes. Las plantas introducidas pueden representar un nuevo hábitat donde las bacterias nativas sean capaces de desarrollar su patogenicidad (Shapiro et al., 2018). En resumen, el gradiente de modernización (Figura 2) se encuentra altamente asociado a la devastación y pérdidas económicas a causa del ataque de bacterias y plagas de hongos o insectos. Esto ocasiona que la relación costo/beneficio del uso de estas prácticas no sea sostenible. Los efectos de la modernización también están altamente asociados a las alteraciones en la microbiota y a la forma en que las poblaciones bacterianas pueden adaptarse a ambientes diferentes (Tikhonovich \& Provorov, 2011); sin embargo, los detalles moleculares de estas interacciones son desconocidos.

\section{Efecto de la modernización}

Se reconoce que el gradiente de modernización (Figura 2, abajo) repercute negativamente en la biodiversidad microbiana de los agroecosistemas (Lupatini, Korthals, de Hollander, Janssens \& Kuramae, 2017; Martínez-Romero, Noyola, Taype, MartínezRomero \& Dávila, 2020). Desde los años 90 , se ha reportado que existe una menor microbiodiversidad en hábitats modificados 
por los humanos, comparados con los ambientes naturales (V. Torsvik, Sørheim \& Goksøyr, 1996). Los agroecosistemas tradicionales, o bien, los agroecosistemas de cultivos orgánicos, serían un punto intermedio en el que la microbiota presenta diferencias con respecto tanto a los ambientes naturales, como a los agroecosistemas modernos (Hartmann, Frey, Mayer, Mäder \& Widmer, 2015; V. Torsvik et al., 1996) (Figura 2).

Los estudios orientados a analizar el efecto que tiene la modernización sobre la estructura de la microbiota en los agroecosistemas, normalmente comparan métodos de manejo convencionales contra sistemas orgánicos de baja labranza o bajos insumos. Los resultados indican que los cultivos orgánicos presentan una diversidad más alta, más riqueza y menos homogeneidad en la microbiota del suelo; también indican que la cantidad y calidad de fertilizantes aplicada en los agroecosistemas modernos son la variable más importante para explicar los cambios en los microbiomas entre ambos sistemas (Hartmann et al., 2015). Se ha demostrado que, en cultivos orgánicos, las comunidades microbianas en la rizosfera tienen redes de interacciones inter-especies más complejas, así como una mayor abundancia de taxas centrales, comparados con los sistemas convencionales (Banerjee et al., 2019).

Además, se encontró que en los cultivos de rotación, la diversidad total de bacterias y arqueas era mayor cuando se aplicaba labranza mínima y que la diversidad microbiana se incrementaba con la profundidad del suelo (Schmidt, Gravuer, Bossange, Mitchell \& Scow, 2018). En el mismo estudio, se observó que la presencia de plantas asociadas provoca un aumento en el número total de bacterias así como en la cantidad y variedad de carbono disponible (Schmidt et al., 2018). Esto último modifica a la microbiota, dado que se favorece la presencia de microorganismos con capacidades metabólicas más amplias. Un estudio reciente comparó la aplicación de fertilizantes químicos con la aplicación de abono en un cultivo de rotación (trigo y maíz) (Wang et al., 2020). Se encontró que las propiedades del suelo se modificaron con ambos tratamientos. Mientras que la aplicación de fertilizantes químicos solamente disminuyó el pH del suelo, la fertilización con abono disminuyó el pH, así como la relación Carbono/ Nitrógeno y, además, aumentó la materia orgánica, Carbono y Nitrógeno total y la disponibilidad de Fósforo y Potasio. También se encontraron diferencias entre las comunidades microbianas del suelo de ambos tratamientos. La aplicación de abono aumentó la abundancia microbiana, así como la diversidad alfa (número de especies en la comunidad) y la abundancia relativa de Actinobacterias y Firmicutes. En contraste, la diversidad alfa disminuyó con la aplicación de fertilizantes químicos (Wang et al., 2020).

\section{Efecto de la domesticación}

La domesticación de las plantas también ha ocasionado que estas recluten microorganismos distintos a los de sus ancestros
(Martínez-Romero et al., 2020). Por ejemplo, el microbioma de la rizosfera de dos variedades de frijol, una silvestre y otra domesticada, presenta cambios asociados a la estructura de sus raíces (Pérez-Jaramillo et al., 2017). En este estudio se demostró que los phyla Bacteroidetes, Verrucomicrobiay Planctomycetes son más abundantes en las variedades silvestres, mientras que los phyla Actinomicetos y Firmicutes lo son en las variedades domesticadas. Además, se ha comparado la microbiota de la rizosfera del teosinte con la de variedades cultivadas de maíz (Szoboszlay et al., 2015) y se encontró que el teosinte alberga en su rizosfera una comunidad más diversa de bacterias, que la de la rizosfera de maíz dulce. Este fenómeno se ha estudiado en plantas de trigo (Tkacz et al., 2020), donde se demostró que la presencia de un genoma de trigo ancestral (Aegilops tauschii), en el trigo moderno (Triticum aestivum) contribuye al reclutamiento de hongos benéficos (Glomeromycetes) en la raíz, que ayudan a prevenir enfermedades por otros hongos. En otras palabras, la capacidad de las plantas para reclutar a estos hongos se ha perdido durante la domesticación.

La milpa representa, por consiguiente, un hábitat modelo para el estudio de las interacciones planta-bacteria, a través del uso de aislados bacterianos, o bien, para el estudio de comunidades por metagenómica para entender el efecto de los procesos de modernización y domesticación sobre las interacciones. Sin embargo, para lograr el cambio hacia prácticas agrícolas sustentables, y conservar las características de la agricultura tradicional, la microbiología agrícola en la milpa debe desarrollarse adicionalmente en dos vertientes: en primer lugar, debe enfocarse hacia nuevas estrategias científicas y tecnológicas que permitan el descubrimiento, desarrollo y aplicación de productos agrobiológicos; y en segundo lugar, es necesario aprovechar la sabiduría y experiencia de los productores de zonas rurales donde se utiliza la agricultura tradicional.

\section{Nuevas estrategias Para EL ESTUdio de LAS INTERACCIONES PLANTA-BACTERIA EN LA MILPA Y SU USO BIOTECNOLÓGICO}

Como fuente de aislados bacterianos, las milpas ofrecen una gran diversidad de ambientes, plantas hospederas, cepas que aún no se han identificado, etc. Esto es el resultado del trabajo de selección y domesticación por parte de las familias campesinas, quienes obtienen variedades de plantas únicas, y con microbiomas característicos, asociadas a los gustos y preferencias alimenticias específicas de cada región. Sin embargo, es necesario un cambio de paradigma para lograr obtener resultados más efectivos en el desarrollo y uso de los insumos agrobiotecnológicos. Esto es, tanto en la forma de estudiar los aislados microbianos (Timmusk, Behers, Muthoni, Muraya \& Aronsson, 2017), como en la estrategia para aplicarlos en el campo, donde rara vez se comportan igual que en el laboratorio (Sergaki, Lagunas, Lidbury, Gifford \& Schäfer, 2018). 
Aunque los estudios in situ son deseables para lograr comprender cómo ha evolucionado la microbiota asociada a las plantas de la milpa (Chen et al., 2017), la generación de conocimiento sobre las interacciones en la microbiota sólo es posible a través de estrategias experimentales robustas, es decir, con experimentos más estables ante variables no controladas (Zhalnina, Zengler, Newman \& Northen, 2018). En los últimos años, se ha propuesto que el uso de comunidades sintéticas es una alternativa adecuada para este objetivo, debido a que representa un punto intermedio entre el estudio de bacterias cultivables en cultivos puros y la metagenómica (Figura 3) (Kolter \& Chimileski, 2018). Las comunidades sintéticas son grupos de dos o más especies de bacterias cultivables y manejables que pueden ser estudiadas a través de su inoculación, monitoreo y detección en determinado ambiente o condición (soporte físico, hospedero, sustrato, o condición de estrés). Se considera que los sistemas multiespecies son necesarios para descubrir los mecanismos por los que se dan las interacciones entre bacterias, o entre bacterias y hospederos. Esto se vuelve de especial importancia en el contexto agrícola, donde los suelos albergan comunidades complejas y estas se ensamblan en la rizosfera con una estructura y función determinada (Vorholt, Vogel, Carlström \& Müller, 2017).

Aunque el estudio de las comunidades bacterianas, a través de comunidades sintéticas, se inició hace pocos años (Castrillo et al., 2017; Niu et al., 2017; Pishchany et al., 2018), los resultados son prometedores y continuamente dan pie al diseño de nuevas estrategias para buscar comunidades con funciones biológicas novedosas. Además, proponemos que las comunidades sintéticas representan una aproximación positiva para la generación de insumos agrobiotecnológicos, porque en ellas se pueden dar funciones emergentes, que están presentes solamente en una comunidad y no en las bacterias aisladas que la componen. Por ejemplo, se demostró la capacidad de una comunidad sintética ensamblada a partir de siete cepas bacterianas aisladas de la rizosfera de maíz para antagonizar un hongo fitopatógeno in vivo (Niu et al., 2017). Notablemente, ninguna de las cepas aisladas tiene esa actividad. También se ha reportado que en comunidades sintéticas pueden inducirse funciones colectivas emergentes, ausentes en las cepas aisladas, por ejemplo de dispersión y formación de biofilms (McCully, Bitzer, Seaton, Smith \& Silby, 2019; Yannarell, Grandchamp, Chen, Daniels \& Shank, 2019). Ambos son fenotipos favorables para la sobrevivencia de las bacterias en el ambiente. Finalmente, la estructura y la función de una comunidad sintética podrían ser más estables y, por lo tanto, más eficientes al aplicarse en el campo. Es decir, las comunidades son más estables ante cambios ambientales, en comparación con un aislado bacteriano o una formulación en la que no se ha considerado el efecto de las interacciones bacteria-bacteria sobre sus funciones (Awasthi, Singh, Soni, Singh \& Kalra, 2014; Bell, Newman, Silverman, Turner \& Lilley, 2005).
Las comunidades sintéticas como modelo de laboratorio no deben sustituir a los estudios en el campo de la metagenómica; más bien, se espera que sirvan como un complemento y una base de conocimientos sólidos sobre las interacciones en las comunidades bacterianas para ser corroborados a nivel invernadero o en el campo (Vorholt et al., 2017). De igual manera, los estudios que utilicen comunidades sintéticas deben estar fundamentados con estudios genéticos y moleculares, realizados en cultivos de bacterias puros.

\section{CONCLUSIONES Y PERSPECTIVAS}

Las milpas son agroecosistemas donde se albergan múltiples variedades de maíz criollo que han sido seleccionadas a lo largo de milenios por familias de productores locales. Estos agroecosistemas, de gran importancia económica, social y cultural en las zonas rurales, presentan características ecológicas que recientemente han despertado el interés de investigadores de diversas áreas de las ciencias naturales.

La sanidad de las plantas depende en gran medida de las comunidades microbianas asociadas; por lo tanto, la microbiota asociada a plantas en la milpa representa un buen recurso para investigaciones de ciencia básica y sus aplicaciones en la agrobiotecnología. Para esto, las estrategias clásicas de la microbiología para el estudio de aislados bacterianos obtenidos de las milpas, deben enfocarse en la búsqueda de nuevas cepas con potencial como insumos agrobiológicos. Así mismo, la milpa representa un hábitat idóneo para que, a través de las nuevas estrategias de metagenómica, sea posible descubrir las bases ecológicas que dirigen el ensamble de una microbiota sana en las plantas. Además, estas estrategias basadas en secuenciación masiva son útiles para entender el efecto de la modernización y domesticación sobre las comunidades bacterianas asociadas a las plantas en los agroecosistemas. Sin embargo, se necesitan nuevas estrategias de investigación - como el uso de comunidades sintéticas - para lograr el entendimiento de las bases moleculares y ecológicas de las interacciones planta-bacteria en los ambientes complejos de la milpa.

Finalmente, es necesario que las investigaciones microbiológicas en la milpa integren los aspectos sociales de las comunidades donde se mantienen estos agroecosistemas. Un enfoque transdisciplinario debe incorporar las áreas de desarrollo regional, antropología y etnoecología para que la ciencia básica y sus aplicaciones tengan impacto social, ambiental y económico positivo para las familias que mantienen las milpas. Además, es indispensable que los recursos genéticos que ofrece la microbiodiversidad de la milpa pertenezcan a los productores locales, como lo establece el Protocolo de Nagoya (Morgera, Tsioumani \& Buck, 2015). En este sentido, la "etnomicrobiología" - el estudio de los factores biológicos, ecológicos y culturales que intervienen en las interacciones entre humanos y microorganismos (Souza 
et al., 1997) - es necesaria para entender las interacciones planta-bacteria en la milpa, en un contexto donde las personas, sus prácticas, preferencias alimenticias y ornamentales, además de sus tradiciones, juegan un papel fundamental (Angélica Cibrián, comunicación personal). Asimismo, la ciencia realizada en la milpa debe tener como complemento el intercambio de conocimientos con los productores, respeto a sus tradiciones, y sustentabilidad, incorporando a estudiantes, investigadores e instituciones locales (Mayra de la Torre, comunicación personal).

\section{Agradecimientos}

Los autores agradecen a Juan Pablo Pérez por proporcionar las fotografías de las milpas del Estado de Hidalgo y a Zahira Zorrilla por realizar las ilustraciones de las figuras 2 y 3. Gabriela Gastélum recibe la beca CONACYT 761832 para estudios de doctorado. Jorge Rocha recibió apoyo del proyecto FOMIX Hidalgo 267837 y FORDECYT 296368 y es participante del proyecto de Cátedras CONACYT 476.

\section{REFERENCIAS}

Agaisse, H. \& Lereclus, D. (1995). How does Bacillus thuringiensis produce so much insecticidal crystal protein? Journal of Bacteriology, 177(21), 6027-6032. https://doi. org/10.1128/jb.177.21.6027-6032.1995

Aguirre-Von-Wobeser, E., Rocha-Estrada, J., Shapiro, L. R. \& De La Torre, M. (2018). Enrichment of Verrucomicrobia, Actinobacteria and Burkholderiales drives selection of bacterial community from soil by maize roots in a traditional milpa agroecosystem. PLoSONE, 13(12), e0208852.https:// doi.org/10.1371/journal.pone.0208852

Awasthi, A., Singh, M., Soni, S. K., Singh, R. \& Kalra, A. (2014). Biodiversity acts as insurance of productivity of bacterial communities under abiotic perturbations. ISME Journal, 8(12), 2445-2452. https://doi.org/10.1038/ismej.2014.91

Banerjee, S., Walder, F., Büchi, L., Meyer, M., Held, A. Y., Gattinger, A., Keller, T., Charles, R. \& Heijden van der, M. G.A.(2019).Agricultural intensification reduces microbial network complexity and the abundance of keystone taxa in roots. ISME Journal, 13(7), 1722-1736. https://doi. org/10.1038/s41396-019-0383-2

Bargaz, A., Lyamlouli, K., Chtouki, M., Zeroual, Y. \& Dhiba, D. (2018). Soil microbial resources for improving fertilizers efficiency in an integrated plant nutrient management system. Frontiers in Microbiology, 9, 1606. https://doi. org/https://doi.org/10.3389/fmicb.2018.01606

Bell, T., Newman, J. A., Silverman, B. W., Turner, S. L. \& Lilley, A. K. (2005). The contribution of species richness and composition to bacterial services. Nature, 436(7054), 1157-1160. https://doi.org/https://doi.org/10.1038/ nature 03891

Benítez, T., Rincón, A. M., Limón, M. C. \& Codon, A. C. (2004). Biocontrol mechanisms of Trichoderma strains. International Microbiology, 7(4), 249-260.
Berendsen, R. L., Pieterse, C. M. J. \& Bakker, P.A. H. M. (2012). The rhizosphere microbiome and plant health. Trends in Plant Science, 17(8), 478-486. https://doi.org/https://doi. org/10.1016/j.tplants.2012.04.001

Bhattacharyya, P. N. \& Jha, D. K. (2012). Plant growthpromoting rhizobacteria (PGPR): emergence in agriculture. World Journal of Microbiology and Biotechnology, 28(4), 1327-1350. https://doi.org/https://doi.org/10.1007/s11274011-0979-9

Bulgarelli, D., Rott, M., Schlaeppi, K., van Themaat, E. V. L., Ahmadinejad, N., Assenza, F., Rauf, P., Huettel, B., Reinhardt, R. \& Schmelzer, E. (2012). Revealing structure and assembly cues for Arabidopsis root-inhabiting bacterial microbiota. Nature, 488(7409), 91-95. https://doi.org/ https://doi.org/10.1038/nature11336

Bulgarelli, D., Schlaeppi, K., Spaepen, S., Van Themaat, E. V. L. \& Schulze-Lefert, P. (2013). Structure and functions of the bacterial microbiota of plants. Annual Review of Plant Biology, 64(1), 807-838. https://doi.org/https://doi. org/10.1146/annurev-arplant-050312-120106

Castrillo, G., Teixeira, P. J. P. L., Paredes, S. H., Law, T. F., de Lorenzo, L., Feltcher, M. E., Finkel, O. M., Breakfield, N. W., Mieczkowski, P. \& Jones, C. D. (2017). Root microbiota drive direct integration of phosphate stress and immunity. Nature, 543(7646), 513-518. https://doi. org/https://doi.org/10.1038/nature21417

Chen, Y. H., Shapiro, L. R., Benrey, B. \& Cibrián-Jaramillo, A. (2017). Back to the origin: in situ studies are needed to understand selection during crop diversification. Frontiers in Ecology and Evolution, 5, 125. https://doi.org/https:// doi.org/10.3389/fevo.2017.00125

Clayton, G. W., Rice, W. A., Lupwayi, N. Z., Johnston, A. M., Lafond, G. P., Grant, C. A. \& Walley, F. (2004). Inoculant formulation and fertilizer nitrogen effects on field pea: Crop yield and seed quality. Canadian Journal of Plant Science, 84(1), 89-96. https://doi.org/https://doi. org/10.4141/P02-090

CONABIO. (2020). La milpa. Recuperado el 3 de septiembre del2020,dehttps://www.biodiversidad.gob.mx/diversidad/ sistemas-productivos/milpa

Depoorter, E., Bull, M. J., Peeters, C., Coenye, T., Vandamme, P. \& Mahenthiralingam, E. (2016). Burkholderia: an update on taxonomy and biotechnological potential as antibiotic producers. Applied Microbiology and Biotechnology, 100(12), 5215-5229. https://doi.org/https:// doi.org/10.1007/s00253-016-7520-x

Dowling, D. N. \& O'Gara, F. (1994). Metabolites of Pseudomonas involved in the biocontrol of plant disease. Trends in Biotechnology, 12(4), 133-141. https://doi.org/ https://doi.org/10.1016/0167-7799(94)90091-4

Ebel, R., Pozas Cárdenas, J. G., Soria Miranda, F. \& Cruz González, J. (2017). Manejo orgánico de la milpa: rendimiento de maíz, frijol y calabaza en monocultivo y policultivo. Terra Latinoamericana, 35(2), 149-160. 
Fierer, N. (2017). Embracing the unknown: disentangling the complexities of the soil microbiome. Nature Reviews Microbiology, 15(10), 579-590. https://doi.org/https://doi. org/10.1038/nrmicro.2017.87

Franche, C., Lindström, K. \& Elmerich, C. (2009). Nitrogenfixing bacteria associated with leguminous and nonleguminous plants. Plant and Soil, 321(1-2),35-59. https:// doi.org/https://doi.org/10.1007/s11104-008-9833-8

Ghosh, A., Mehta, A. \& Khan, A. M. (2019). Metagenomic analysis and its applications. In Encyclopedia of bioinformatics and computational biology (pp. 184-193). Oxford: Academic Press.

Hartmann, M., Frey, B., Mayer, J., Mäder, P. \& Widmer, F. (2015). Distinct soil microbial diversity under long-term organic and conventional farming. ISME Journal, 9(5), 1177-1197. https://doi.org/10.1038/ismej.2014.210

Hathaway, M. D. (2016). Agroecology and permaculture: addressing key ecological problems by rethinking and redesigning agricultural systems. Journal of Environmental Studies and Sciences, 6(2), 239-250. https://doi.org/https:// doi.org/10.1007/s13412-015-0254-8

Herrmann, L. \& Lesueur,D. (2013). Challenges of formulation and quality of biofertilizers for successful inoculation. Applied Microbiologyand Biotechnology, 97(20), 8859-8873. https:// doi.org/https://doi.org/10.1007/s00253-013-5228-8

Hirsch, P. R. \& Mauchline, T. H. (2015). The importance of the microbial $\mathrm{N}$ cycle in soil for crop plant nutrition. Advances in Applied Microbiology, 93, 45-71.https://doi.org/https:// doi.org/10.1016/bs.aambs.2015.09.001

Howell, C. R. (2003). Mechanisms employed by Trichoderma species in the biological control of plant diseases: the history and evolution of current concepts. Plant Disease, 87(1), 4-10. https://doi.org/https://doi.org/10.1094/ PDIS.2003.87.1.4

Janda, J. M. \& Abbott, S. L. (2007). 16S rRNA gene sequencing for bacterial identification in the diagnostic laboratory: pluses, perils, and pitfalls. Journal of Clinical Microbiology, 45(9), 2761-2764. https://doi.org/http://doi.org/10.1128/ JCM.01228-07

Jerónimo, A. S. (2009). Análisis de la agricultura de temporal en México y su relación con las cuestiones climáticas: el caso maíz y frijol. Universidad Autónoma Agraria Antonio Narro. Recuperado de http://repositorio.uaaan. $\mathrm{mx}: 8080 / \mathrm{xmlui} /$ bitstream/handle/123456789/5234/ T17603 SANTIAGO JERONIMO\%2C ABEL TESIS. pdf? sequence $=1$ yisAllowed $=y$

Kaminsky, L. M., Trexler, R. V, Malik, R. J., Hockett, K. L. $\&$ Bell, T. H. (2019). The inherent conflicts in developing soil microbial inoculants. Trends in Biotechnology, 37(2), 140-151. https://doi.org/https://doi.org/10.1016/j. tibtech.2018.11.011

Khush, G. S. (2001). Green revolution: the way forward. Nature Reviews Genetics, 2(10), 815-822. https://doi.org/https:// doi.org/10.1038/35093585
Kolter, R. \& Chimileski, S. (2018). The end of microbiology. Environmental Microbiology, 20(6), 1955-1959. https:// doi.org/10.1111/1462-2920.14240

Kremmydas, G. F., Tampakaki, A. P. \& Georgakopoulos, D. G. (2013). Characterization of the biocontrol activity of Pseudomonas fluorescens strain $\mathrm{X}$ reveals novel genes regulated by glucose. PLoS One, 8(4), e61808. https://doi. org/https://doi.org/10.1371/journal.pone.0061808

Levy, S. E. \& Myers, R. M. (2016). Advancements in nextgeneration sequencing. Annual Review of Genomics and Human Genetics, 17(1), 95-115.https://doi.org/https://doi. org/10.1146/annurev-genom-083115-022413

Liu, A., Contador, C. A., Fan, K. \& Lam, H.-M. (2018). Interaction and regulation of carbon, nitrogen, and phosphorus metabolisms in root nodules of legumes. Frontiers in Plant Science, 9, 1860. https://doi.org/https:// doi.org/10.3389/fpls.2018.01860

Lozada-Aranda, M., Yanes, A. M., Ponce-Mendoza, A., Burgeff, C., Orjuela-R., M. A. \& Galindo., O. O. (2018). Milpas de México. Oikos, 9, 10-12.

Lundberg, D. S., Lebeis, S. L., Paredes, S. H., Yourstone, S., Gehring, J., Malfatti, S., Tremblay, J., Engelbrektson, A., Kunin, V. \& Del Rio, T. G. (2012). Defining the core Arabidopsis thaliana root microbiome. Nature, 488(7409), 86-90.https://doi.org/https://doi.org/10.1038/ nature 11237

Lupatini, M., Korthals, G. W., de Hollander, M., Janssens, T. K. S. \& Kuramae, E. E. (2017). Soil microbiome is more heterogeneous in organic than in conventional farming system. Frontiers in Microbiology, 7, 2064. https://doi. org/https://doi.org/10.3389/fmicb.2016.02064

Maiden, M. C. J. (2006). Multilocus sequence typing of bacteria. Annual Review of Microbiology., 60(1), 561-588. https://doi.org/https://doi.org/10.1146/annurev. micro.59.030804.121325

Martínez-Romero, E., Noyola, J. L. A., Taype, N. T., MartínezRomero, J. \& Dávila, D. Z. (2020). Plant microbiota modified by plant domestication. Systematic and Applied Microbiology, 43(5), 126106. https://doi.org/https://doi. org/10.1016/j.syapm.2020.126106

Matson, P. A., Parton, W. J., Power, A. G. \& Swift, M. J. (1997). Agricultural intensification and ecosystem properties. Science, 277(5325), 504-509. https://doi.org/10.1126/ science.277.5325.504

Mauro, A., Garcia-Cela, E., Pietri, A., Cotty, P. J. \& Battilani, P. (2018). Biological control products for aflatoxin prevention in Italy: commercial field evaluation of atoxigenic Aspergillus flavus active ingredients. Toxins, 10(1), 30. https://doi.org/https://doi.org/10.3390/toxins10010030

McCully, L. M., Bitzer,A. S., Seaton, S. C., Smith, L. M. \& Silby, M. W. (2019). Interspecies Social Spreading: Interaction between Two Sessile Soil Bacteria Leads to Emergence of Surface Motility. MSphere, 4(1), e00696-18. https://doi. org/10.1128/msphere.00696-18 
Méndez-García, C., Bargiela, R., Martínez-Martínez, M. \& Ferrer, M. (2018). Metagenomic protocols and strategies. In Metagenomics (pp. 15-54). Elsevier. https://doi.org/https:// doi.org/10.1016/B978-0-08-102268-9.00002-1

Milner, R. J. (1994). History of Bacillus thuringiensis. Agriculture, Ecosystems \& Environment,49(1), 9-13.https:// doi.org/https://doi.org/10.1016/0167-8809(94)90014-0

Mitter, B., Brader, G., Pfaffenbichler, N. \& Sessitsch, A. (2019). Next generation microbiome applications for crop production - limitations and the need of knowledge-based solutions. Current Opinion in Microbiology, 49, 59-65. https://doi.org/https://doi.org/10.1016/j.mib.2019.10.006

Morgera, E., Tsioumani, E. \& Buck, M. (2015). Unraveling the Nagoya Protocol. Brill. Recuperado de http://www.jstor. org/stable/10.1163/j.ctt1w76vvq

Mus, F., Crook, M. B., Garcia, K., Costas, A. G., Geddes, B. A., Kouri, E. D., Paramasivan, P., Ryu, M., Oldroyd, G. E. D. \& Poole, P. S. (2016). Symbiotic nitrogen fixation and the challenges to its extension to nonlegumes. Applied and Environmental Microbiology, 82(13), 3698-3710. https:// doi.org/https://doi.org/10.1128/AEM.01055-16

Niu, B., Paulson, J. N., Zheng, X. \& Kolter, R. (2017). Simplified and representative bacterial community of maize roots. Proceedings of the National Academy of Sciences, 114(12), E2450-E2459. https://doi.org/10.1073/pnas.1616148114

Peiffer, J. A., Spor, A., Koren, O., Jin, Z., Tringe, S. G., Dangl, J. L., Buckler, E. S. \& Ley, R. E. (2013). Diversity and heritability of the maize rhizosphere microbiome under field conditions. Proceedings of the National Academy of Sciences, 110(16), 6548-6553. https://doi.org/https://doi. org/10.1073/pnas. 1302837110

Pérez-Jaramillo, J. E., Carrión, V. J., Bosse, M., Ferrão, L. F. V, de Hollander, M., Garcia, A. A. F., Ramírez, C.A., Mendes, R. \& Raaijmakers, J. M. (2017). Linking rhizosphere microbiome composition of wild and domesticated Phaseolus vulgaris to genotypic and root phenotypic traits. The ISME Journal, 11(10), 2244-2257. https://doi.org/ https://doi.org/10.1038/ismej.2017.85

Pérez-Jaramillo, J. E., Mendes, R. \& Raaijmakers, J. M. (2016). Impact of plant domestication on rhizosphere microbiome assembly and functions. Plant Molecular Biology, 90(6), 635-644. https://doi.org/https://doi.org/10.1007/s11103015-0337-7

Pershina, E. V, Ivanova, E. A., Korvigo, I. O., Chirak, E. L., Sergaliev, N. H., Abakumov, E. V, Provorov, N. A. \& Andronov, E. E. (2018). Investigation of the core microbiome in main soil types from the East European plain. Science of the Total Environment, Vols. 631-632, 1421-1430. https:// doi.org/https://doi.org/10.1016/j.scitotenv.2018.03.136

Pishchany, G., Mevers, E., Ndousse-Fetter, S., Horvath, D. J., Paludo, C. R., Silva-Junior, E. A., Koren, S., Skaar, E. P., Clardy, J. \& Kolter, R. (2018). Amycomicin is a potent and specific antibiotic discovered with a targeted interaction screen. Proceedings of the National Academy of Sciences, 115(40), 10124-10129. https://doi.org/https:// doi.org/10.1073/pnas.1807613115

Qiu, Z., Egidi, E., Liu, H., Kaur, S. \& Singh, B. K. (2019). New frontiers in agriculture productivity: Optimised microbial inoculants and in situ microbiome engineering. Biotechnology Advances, 37(6), 107371. https://doi.org/ https://doi.org/10.1016/j.biotechadv.2019.03.010

Quince, C., Walker, A. W., Simpson, J. T., Loman, N. J. \& Segata, N. (2017). Shotgun metagenomics, from sampling to analysis. Nature Biotechnology, 35(9), 833-844. https:// doi.org/https://doi.org/10.1038/nbt.3935

Rebollar, E.A., Sandoval-Castellanos, E., Roessler, K., Gaut, B. S., Alcaraz, L. D., Benítez, M. \& Escalante, A. E. (2017). Seasonal changes in a maize-based polyculture of central Mexico reshape the co-occurrence networks of soil bacterial communities. Frontiers in Microbiology, 8, 2478. https:// doi.org/10.3389/fmicb.2017.02478

Rodríguez, A. \& Arias, L. M. (2014). La milpa y el maizal: retos al desarrollo rural en México y Perú. Etnobiología, 12(3), 76-89.

Salcedo, S., De La O, A. \& Guzmán, S. (2014). El concepto de agricultura familiar en América Latina y el caribe. Agricultura Familiar En América Latina y El Caribe: Recomendaciones de Política, 17-34.

Sanchis, V. (2011). From microbial sprays to insect-resistant transgenic plants: history of the biospesticide Bacillus thuringiensis. A review. Agronomy for Sustainable Development, 31(1), 217-231. https://doi.org/10.1051/ agro/2010027

Santhanam, R., Weinhold, A., Goldberg, J., Oh, Y. \& Baldwin, I. T. (2015). Native root-associated bacteria rescue a plant from a sudden-wilt disease that emerged during continuous cropping. Proceedings of the National Academy of Sciences, 112(36), E5013-E5020.https://doi.org/https:// doi.org/10.1073/pnas.1505765112

Santillán, M. L. (2014). La milpa, tradición milenaria de agricultura familiar. Recuperado el 3 de septiembre del 2020, de http://ciencia.unam.mx/leer/356/La_milpa_tradicion

Schmidt, R., Gravuer, K., Bossange, A. V, Mitchell, J. \& Scow, K. (2018). Long-term use of cover crops and no-till shift soil microbial community life strategies in agricultural soil. PLoS One, 13(2), e0192953. https://doi.org/https:// doi.org/10.1371/journal.pone.0192953

Sergaki, C., Lagunas, B., Lidbury, I., Gifford, M. L. \& Schäfer, P. (2018). Challenges and approaches in microbiome research: from fundamental to applied. Frontiers in Plant Science, 9, 1205. https://doi.org/https://doi.org/10.3389/ fpls.2018.01205

Shade, A. \& Handelsman, J. (2012). Beyond the Venn diagram: the hunt for a core microbiome. Environmental Microbiology, 14(1), 4-12. https://doi.org/https://doi. org/10.1111/j.1462-2920.2011.02585.x

Shapiro, L. R., Paulson, J. N., Arnold, B. J., Scully, E. D., Zhaxybayeva, O., Pierce, N. E., Rocha, J., Klepac-Ceraj, V., 
Holton, K. \& Kolter, R. (2018). An introduced crop plant is driving diversification of the virulent bacterial pathogen Erwinia tracheiphila. MBio, 9(5), e01307-18. https://doi. org/10.1128/mBio.01307-18

Sinclair, T. R. \& Nogueira, M. A. (2018). Selection of host-plant genotype: the next step to increase grain legume $\mathrm{N}_{2}$ fixation activity. Journal of Experimental Botany, 69(15), 3523-3530. https://doi.org/https://doi.org/10.1093/jxb/ery115

Sivasakthi, S., Usharani, G. \& Saranraj, P. (2014). Biocontrol potentiality of plant growth promoting bacteria (PGPR)Pseudomonas fluorescens and Bacillus subtilis: A review. African Journal of Agricultural Research, 9(16), 1265-1277. https://doi.org/https://doi.org/10.5897/AJAR2013.7914

Souza, V., Bain, J., Silva, C., Bouchet, V., Valera, A., Marquez, E. \&Eguiarte, L.E.(1997). Ethnomicrobiology: do agricultural practices modify the population structure of the nitrogen fixing bacteria Rhizobium etli biovar phaseoli. Journal of Ethnobiology, 17, 249-266.

Stukenbrock, E. H. \& McDonald, B. A. (2008). The Origins of Plant Pathogens in Agro-Ecosystems. Annual Review of Phytopathology, 46(1), 75-100. https://doi.org/10.1146/ annurev.phyto.010708.154114

Szoboszlay, M., Lambers, J., Chappell, J., Kupper, J. V, Moe, L. A. \& McNear Jr, D. H. (2015). Comparison of root system architecture and rhizosphere microbial communities of Balsas teosinte and domesticated corn cultivars. Soil Biology and Biochemistry, 80, 34-44. https://doi.org/https://doi. org/10.1016/j.soilbio.2014.09.001

Thomas, F., Hehemann, J.-H., Rebuffet, E., Czjzek, M. \& Michel, G. (2011). Environmental and gut bacteroidetes: the food connection. Frontiers in Microbiology, 2, 93. https://doi. org/https://doi.org/10.3389/fmicb.2011.00093

Thompson, L. R., Sanders, J. G., McDonald, D., Amir, A., Ladau, J., Locey, K. J., Prill, R. J., Tripathi, A. G., Sean M. \& Ackermann, G. (2017). A communal catalogue reveals Earth's multiscale microbial diversity. Nature, 551(7681), 457-463. https://doi.org/https://doi. org/10.1038/nature24621

Tikhonovich, I. A. \& Provorov, N. A. (2011). Microbiology is the basis of sustainable agriculture: an opinion. Annals of Applied Biology, 159(2), 155-168. https://doi.org/https:// doi.org/10.1111/j.1744-7348.2011.00489.x

Tilman, D., Balzer, C., Hill, J. \& Befort, B. L. (2011). Global food demand and the sustainable intensification of agriculture. Proceedings of the National Academy of Sciences, 108(50), 20260-20264. https://doi.org/https://doi.org/10.1073/ pnas. 1116437108

Timmusk, S., Behers, L., Muthoni, J., Muraya, A. \& Aronsson, A.-C. (2017). Perspectives and challenges of microbial application for crop improvement. Frontiers in Plant Science, 8, 49. https://doi.org/https://doi.org/10.3389/ fpls.2017.00049

Tkacz, A., Pini, F., Turner, T. R., Bestion, E., Simmonds,
J., Howell, P., Greenland, A.C., Jitender E., David M. \& Uauy, C. (2020). Agricultural selection of wheat has been shaped by plant-microbe interactions. Frontiers in Microbiology, 11, 132. https://doi.org/https://doi. org/10.3389/fmicb.2020.00132

Torsvik, V., Sørheim, R. \& Goksøyr, J. (1996). Total bacterial diversity in soil and sediment communities - A review. Journal of Industrial Microbiology and Biotechnology, 17, 170-178. https://doi.org/https://doi.org/10.1007/ BF01574690

Torsvik, V., Goksøyr, J. \& Daae, F. L. (1990). High diversity in DNA of soil bacteria. Applied and Environmental Microbiology, 56(3), 782-787. https://doi.org/https://doi. org/0099-2240/90/030782-06\$02.00/0

Van Deynze, A., Zamora, P., Delaux, P. M., Heitmann, C., Jayaraman, D., Rajasekar, S., Graham, D., Maeda, J., Gibson, D., Schwartz, K. D., Berry, A. M., Bhatnagar, S., Jospin, G., Darling, A., Jeannotte, R., Lopez, J., Weimer, B. C., Eisen, J. A., Shapiro, H. Y., Ané, J. M. \& Bennett, A. B. (2018). Nitrogen fixation in a landrace of maize is supported by a mucilage-associated diazotrophic microbiota. PLoS Biology, 16(8), e2006352. https://doi.org/10.1371/journal. pbio. 2006352

van Veen, J. A., van Overbeek, L. S. \& van Elsas, J. D. (1997). Fate and activity of microorganisms introduced into soil. Microbiology and Molecular Biology Reviews, 61(2), 121135.https://doi.org/https://doi.org/1092-2172/97/\$04.0010

Vorholt, J. A., Vogel, C., Carlström, C. I. \& Müller, D. B. (2017). Establishing causality: opportunities of synthetic communities for plant microbiome research. Cell Host \& Microbe, 22(2), 142-155. https://doi.org/https://doi. org/10.1016/j.chom.2017.07.004

Wang, F., Han, W., Chen, S., Dong, W., Qiao, M., Hu, C. \& Liu, B. (2020). Fifteen-Year Application of Manure and Chemical Fertilizers Differently Impacts Soil ARGs and Microbial Community Structure. Frontiers in Microbiology, 11, 62. https://doi.org/https://doi.org/10.3389/fmicb.2020.00062

Wilson, E. O. (1994). Naturalist. Washington, DC: Island Press.

Woese, C. R. (1987). Bacterial evolution. Microbiological Reviews, 51(2), 221-271.

Woodruff, H. B. (1980). Natural products from microorganisms. Science, 208(4449), 1225-1229. https://doi.org/10.1126/ science. 7375932

Yannarell, S. M., Grandchamp, G. M., Chen, S.-Y., Daniels, K. E. \& Shank, E. A. (2019). A Dual-Species Biofilm with Emergent Mechanical and Protective Properties. Journal of Bacteriology, 201(18), e00670-18. https://doi.org/10.1128/ jb.00670-18

Zhalnina, K., Zengler, K., Newman, D. \& Northen, T. R. (2018). Need for laboratory ecosystems to unravel the structures and functions of soil microbial communities mediated by chemistry.MBio, 9(4), e01175-18. https://doi.org/10.1128/ mBio.01175-18 